symposium of special diagnostic aids, of which the overall editor is C. Paul Hodgkinson, M.D.

In this section, the more recent and not so recent aids in making gynaecological diagnosis more accurately are described and reviewed.

It starts with a very fair review of the way of staging uterine cancer and inevitably proceeds to discussion of cytology, including more exotic methods of obtaining cytological specimens.

Culdocentesis and culdoscopy have small chapters.

There is an excellent summary of the indications and contraindications and dangers of hystersalpingography and there are also good reviews of the value of $X$-ray pelvimetry and of soft tissue placentography together with a new technique of urethrocystograms.

The diagnosis of toxaemia of pregnancy is treated rather superficially.

The second half of the book is devoted to abnormal uterine bleeding under the editorship of John I. Brewer, M.D. The causes are reviewed and unusual conditions like bleeding in children are written about.

There is a very sensible chapter on menopausal and postmenopausal bleeding and another small one on the psychosomatic aspects of bleeding.

Altogether, this section maintains the high standard set by the previous books in the first year's volume.

\section{EAR, NOSE AND THROAT DYSFUNCTION DUE TO DEFICIENCIES AND IMBALANCES}

By Sam E. Roberts, M.D. Pp. xxiii +305 , with 57 illustrations. Oxford: Blackwell Scientific Publications. 1957. 63s.

The basis of the book's raison d'etre, and a wholly laudable one, is that many disorders in the field of otolaryngology are the localized manifestations of a constitutional disease.

The author has candidly stated that much in the book is founded on clinical observation and the results described are, in part, subjective. These deficiencies and imbalances are nutritional, electrolytic, hormonal, acid base and insulin sugar and the sub-clinical conditions thereof have not been helped and may have been impeded by available laboratory tests.

Many working hypotheses have been used by the author to support his views. The basis of all treatment throughout the book is the therapeutic test and is reinforced by many case reports-these are not wholly convincing. The correction of gonadal imbalance is a constant theme and would appear to contribute to many conditions such as vascular headache, Meniere's Disease, acoustic nerve and sinus dysfunctions.

The author says that he is not expecting total acceptance of his views, even anticipating vehement opposition.

This is a fair assessment.

P.A.

\section{SURGEON AT ARMS}

By Daniel Paul. Pp. 227, with illustrations. London: William Heinemann Ltd. 1958. r6s.

Daniel Paul conceals the identity of an orthopaedic surgeon who as a member of the Parachute Field Ambulance was captured at Arnhem. After many adventures and frustrating delay he managed to escape back to the British line. Most of the story is concerned with his hiding with the Dutch Resistance, and interesting as this is, the Reviewer personally would have liked to hear more about the Arnhem Battle.

However, the book is an exciting story written about a man of obvious courage and determination and should have a wide appeal both to the general public and to doctors, particularly those who have served with Airborne Forces.

D.W.S.G.

\section{PSYCHIATRY IN THE BRITISH ARMY IN} THE SECOND WORLD WAR

By R. H. Ahrenfeldt. Pp. xv + 312. London: Routledge and Kegan Paul Ltd. 1958. 35 s.

The most striking thing about this book is the diversity of function of the army psychiatrist which it describes. Many of the widely disparate duties can only be related to mental hygiene by stretching the imagination, and only two of the ten chapters describe traditional medical work in caring for and treating soldiers with psychiatric disabilities. The remainder of the book records the work of the psychiatrist in such unfamiliar fields as personnel selection, service discipline and morale, training, civil resettlement, and the like. This is not to negate the value of the book; on the contrary, it throws a new light on the contribution which psychiatry made to acute social problems in a time of national emergency, and so fills many of the gaps left by the more conventional medical histories of the war.

Looking back in retrospect and with the comprehensive overview provided by available documents and postwar surveys, much of this work, which was essentially on a trial-and-error basis, was perhaps less important than the author makes out. Few would certainly agree with the author that in officer selection and in the assessment of temperamental factors 'psychology is the handmaid of psychiatry.' The study of behaviour of normal individuals, is of course, Psychology's special province, and readers capable of differentiating these two disciplines will quickly realise that the major function of this book has been to put the case for Military Psychology; it is noteworthy that the psychiatrists who, in the author's opinion, made the most significant contributions to this aspect of service needs were in fact men who were better known in psychological circles than psychiatric ones. Dr. J. D. Sutherland, former President of the British Psychological Society, is perhaps the 
best example of this point. One cannot deny that the psychiatrist played a useful part in these psychological activities. At a time when the academically-trained psychologist was very much a rara avis, no one was better equipped to deal with problems of this sort than the psychiatrist. In recording his work the author has a justifiable raison d'etre for his book. It supplements other histories without duplication, and makes absorbing reading. Despite its factual presentation the author contrives to make an exciting narrative which conveys empathically that time of difficulty and frustration when 'compromise' and 'improvise' were the keywords in service organisation, and places on record a hitherto overlooked function of World War II.psychiatry.

\section{L.R.C.H.}

\section{A PRACTICE OF THORACIC SURGERY}

By A. L. d'Abreu, O.B.E., Ch.M., F.R.C.S. Second Edition. Pp. viii +6 r9, illustrated. London: Edward Arnold Ltd. I958. Ioos.

This book was first published in 1953 and the second edition is most welcome. Its title indicates that it is no theoretical treatise; the book is, in fact, essentially practical and aims to provide background knowledge and foreground information on the modern management of intrathoracic diseases from the surgical viewpoint.

It is divided into sections dealing with normal anatomy and physiology, pleural and pulmoriary infections, tuberculosis, lung tumours and surgery of the heart and mediastinum. The chapter on thoracic injuries and the section devoted to thoracoabdominal surgery should be of the greatest interest and value to the general surgeon.

Dr. Donald, Dr. Astley and Dr. Davison have revised and enlarged their chapters which deal with lung function and the investigation of the patient with heart disease by by angiocardiography and cardiac catheterisation. They have preserved simplicity in their contributions making difficult subjects comprehensible and it is over the common ground that they cover that physician and surgeon must often meet to discuss the practical management of the patient.

The book is profusely illustrated with line drawings and radiographs and the quality of their re- production is excellent. References at the end of each chapter give a balanced selection of the more $\frac{3}{\mathbb{Q}}$ recent articles with those older ones which are land- 0 marks in the development of thoracic surgery. $C$ This book can be very strongly recommended; it $\overrightarrow{\vec{F}}$ is a mine of information written in a most refreshing $\stackrel{+}{+}$ style, and will be found most valuable to the specialist surgeon as a work of reference and $\overline{\bar{N}}$. valuable also to those seeking higher surgical and $\frac{\bar{s}}{\widehat{D}}$ medical qualifications.

A HANDBOOK OF MEDICAL HYPNOSIS $\vec{\circ}$ By G. Ambrose, I.M.S.S.A., and G. Newbold, $\vec{\omega}$ M.B., B.S., M.R.C.S., M.M.S.A., D.R.C.O.G., D.C.H. Second Edition. Pp. xiii +276.0 London: Baillière, Tindall \& Cox. r958. 27s. 6d.

The first edition of this book appeared only two $+\overrightarrow{0}$ years ago and met with considerable success. In + the present revision, the authors have very wisely $\omega_{\sigma}$ taken counsel from their constructive critics, and $Y$ effected a number of improvements, particularly in $\sigma$ what might be called the 'technical side' of hypnosis. These include notes on the physio- logical concomitants of hypnosis and a short section $ᄃ$ on the E.E.G. which really raises more questions than it answers - always a healthy sign in an intro-ductory text. Perhaps a little more may have beeg cited on psychological changes under hypnosis 6 there is some very striking psychometric evidencè available on age regressions and personality changes - since knowledge of these phenomena help to give that complete confidence in the technique which must always be the sine qua non of the successfulo hypnotist.

The layout of the book is relatively unchanged, $\overrightarrow{\vec{B}}$ with introductory chapters on history, theory and 3 legal aspects, followed by a full discussion of ${ }_{\supset}$ medical hypnotism in the various clinical fields: anaesthesia, dermatology, gynaecology, obstetrics, the psychoneuroses, and general medicine. The $\frac{3}{3}$ appendices contain a full copy of the 1952. Hypnotism Act and a summary of the r 955 B.M.A. Report. This book remains the best introduction. to the subject available today and is speciallyo suitable for those anxious to practice what may one 2 day become medicine's principal therapeutic윽 measure.

L.R.C.H. 